\title{
Obituary
}

\section{Dr. William Fisher Enneking}

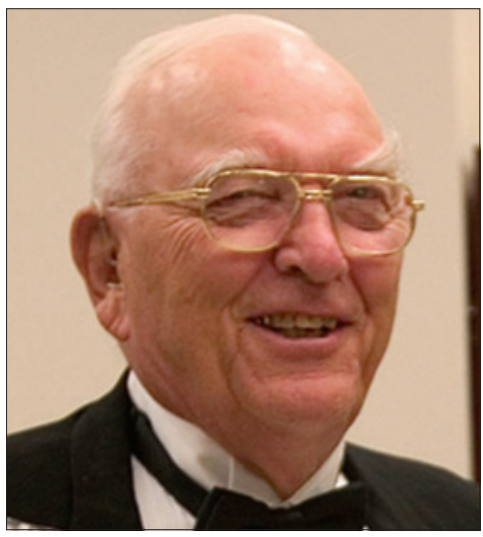

Dr. William Fisher Enneking

(May 9, 1926 to July 18, 2014)

(Pic Courtesy: Webpage of the University of Florida)

Dr. William F Enneking was born in Madison, Wisconsin on $9^{\text {th }}$ May 1926. He graduated from the University of Wisconsin in 1946 and subsequently obtained his MD in 1949 from the same University. Dr. Enneking worked as a resident of Orthopedics in the University of Chicago between 1952 and 1955. He served as an Associate Professor and Chief of Orthopedics at the University of Mississippi between 1956 and 1960. From 1962 onwards he worked as Professor and Chief of Orthopedics, Department of Orthopedic Surgery, University of Florida. From 1980, Dr. Enneking served as the Eugene L Jewett Professor of Orthopedics at the University of Florida until 2005 when he was appointed as Professor Emeritus.

Dr. Enneking had a distinguished Orthopedic career with pioneering work in musculoskeletal oncology. In 1980, he defined oncological margins for bone tumors in his path breaking paper on the management of bone sarcomas. His classification of tumor margins, along with modern chemotherapy, paved the way for successful limb salvage surgeries in sarcomas across the globe.
Dr. Enneking received a number of awards and accolades throughout his career including the prestigious Kappa Delta Award, which he received on two occasions. He served as the President of the American Orthopedic Association between 1983 and 1984 and was the Chairman, Board of Directors of the Musculoskeletal Transplant Foundation. He authored six major books on different aspects of Musculoskeletal Oncology and published more than 100 papers in the International Journals of repute.

Dr. William Enneking passed away peacefully in Florida on July 18, 2014.

There are only few surgeons who have significantly influenced the path of orthopedic practice in a manner in which Dr. Enneking did. His contributions to musculoskeletal oncology have been enormous and will be remembered for generations to come. The application of Dr. Enneking's surgical principals in the treatment of bone tumors has benefited millions of patients across the globe. Dr. William F Enneking will continue to influence our lives.

\section{Mark T Scarborough, Shah Alam Khan ${ }^{1}$}

Department of Orthopaedics and Rehabilitation, University of Florida, College of Medicine, Gainesville, FL 32611 - 2727, USA, ${ }^{1}$ Department of Orthopaedics, All India Institute of Medical Sciences, New Delhi, India E-mail: shahalamkhan70@gmail.com

\begin{tabular}{|l|l|}
\hline \multicolumn{2}{|c|}{ Access this article online } \\
\hline Quick Response Code: & \\
\hline ⿴囗口 & Website: \\
\hline
\end{tabular}

